\title{
The Language Learning Potential of Writing through EFL Students' Processing of Feedback
}

\author{
Florentina Nicolás Conesa \\ Julio Roca de Larios \\ María Ángeles Monteverde \\ Universidad de Murcia
}

Received: 30 June 2017 / Accepted: 26 September 2017

ISSN: $1697-7467$

\begin{abstract}
This study investigates the effects of low L2 proficiency students' processing of two feedback types (direct and indirect) during a written languaging session on the accuracy of their rewritten texts. Data were collected during two weeks and were statistically analysed. The main findings showed that none of the two feedback groups reflected on and understood all the errors on which they received feedback, which in turn determined the accuracy of the rewritten texts. These results open a new window for the investigation of the effectiveness of different feedback types and the language learning potential of writing. The empirical and pedagogical implications of these findings are discussed.
\end{abstract}

Keywords: written languaging, direct feedback, indirect feedback, language learning potential of writing, processing.

EI Potencial de Aprendizaje de Lengua a través de la Escritura basado en el Procesamiento del Feedback en Estudiantes de Inglés como Lengua Extranjera

RESUMEN: Este estudio investiga los efectos del procesamiento de dos tipos de feedback (directo e indirecto) sobre la corrección de textos reescritos en estudiantes de bajo nivel de L2 durante una sesión de verbalización de errores de forma escrita. Los datos fueron recogidos durante dos semanas y analizados estadísticamente. Los resultados principales muestran que ninguno de los dos grupos de feedback reflexionó ni entendió todos los errores que les fueron corregidos, lo que a su vez determinó la corrección lingüistica de los textos reescritos. Estos resultados abren una nueva ventana para la investigación de la efectividad de los diferentes tipos de correcciones y el potencial de aprendizaje de lengua a través de la escritura. Las implicaciones empíricas y pedagógicas del estudio son discutidas.

Palabras clave: verbalización escrita, corrección directa, corrección indirecta, potencial de aprendizaje de lengua basado en la escritura, procesamiento.

\section{INTRODUCTION}

Twenty years ago the field of Second Language Writing (SLW) pedagogy was shaken up by Truscott (1996) claiming that written corrective feedback "does not work and should be abandoned" (2010, p. 334). Truscott (1996) alleged that written corrective feedback (WCF) was not only ineffective on grammatical errors but also had harmful side effects 
since it may encourage learners to simplify their writing in order to avoid those areas they perceive as problematic. Since then, numerous WCF studies have been published about the relationship between learners' L2 accuracy and the degree of explicitness of the feedback provided to them through direct or indirect feedback. Direct feedback is supposed to reduce the confusion in correction by allowing learners to instantly internalize the correct forms provided by the teacher (Chandler, 2003); and to provide learners with the information that is needed for testing their hypotheses about the L2 (Bitchener \& Knoch, 2008), especially if these hypotheses include complex syntactic structures or idiomatic usage (Bitchener, 2012). For these reasons, direct feedback is thought to be especially suitable for learners at lower levels of L2 proficiency and writing ability (Shintani \& Ellis, 2013). In contrast, supporters of indirect feedback argue that indirect correction is more beneficial because it requires learners to engage in feedback processing as a problem-solving activity, thus, helping them to engage in deeper reflection that can lead to long-term acquisition (Bitchener \& Knoch, 2008). However, it has also been claimed that indirect feedback provides learners with insufficient information about complex linguistic errors and that learners must have consolidated L2 knowledge to take full advantage of indirect feedback (Bitchener, 2012).

Recent studies have been consistent in reporting an advantage for direct feedback in ESL settings (cf. Bitchener \& Storch, 2016). Findings indicate that, although both feedback types may be equally effective in the short-term and for non-grammatical errors, only direct feedback is effective in the long-run and for grammatical errors because it can contribute to change learners' implicit knowledge of the language (see Ellis \& Shintani, 2013). These findings are in contrast to Truscott's (2007) assertion that feedback can only be effective for non-grammar errors. However, as pointed out by Bitchener (2012) the role played by some mediating variables on the effects produced by the two feedback types should still be clarified. Some studies that reported better results for direct feedback were conducted with advanced L2 learners or ESL students (Bitchener \& Storch, 2016), and their results were only based on the analyses of the texts produced by the students, without analysing their feedback processing. The effectiveness of WCF should be analysed in relation to the learners' feedback processing and to the students' capacity to understand the error (Mackey et al., 2000) since learners' depth of processing when confronted with feedback has been posited as a crucial element in the possible relationship between feedback and L2 acquisition (Manchón, 2011). Manchón (2011) propounded that written output can promote language learning when learners engage in linguistic processing through noticing and hypothesis testing. This view of writing was described by Manchón (2011) as the writing-to-learn language (WLL) dimension of writing. Along these lines, the language learning potential of writing (LLP) is shown when students do not only look at the corrections provided (either through direct or indirect feedback), which would be representative of simple noticing (Schmidt, 1990), but when they also process feedback, that is, when students engage in reflection on the errors made and propose solutions to them in an oral or written way.

Linguistic reflection on language can take place in its written or oral mode, but it has been usually associated with the oral register due to a misinterpretation of Swain's term (1995) of verbalisation. This is the reason why in 2006 Swain coined the term "languaging" to describe the process, either written or oral, "of making meaning and shaping knowledge and experience through language. It is part of what constitutes learning" (p. 98). Empirical research has shown that languaging mediates learning by drawing learners' attention to language problems and by being an instrument to promote reflection and find a solution to problems bringing to light inconsistencies in knowledge (Swain, 2006). 
Florentina, Julio and María Ángeles The Language Learning Potential of Writing through EFL ...

Research on collaborative writing has shown that languaging can lead to engagement with language at metalinguistic levels (Fortune \& Thorp, 2001) and to an increase in written accuracy (Kuiken \& Vedder, 2008). However, in collaborative writing the reflection on language by means of writing cannot be isolated from the effects of oral interaction, which in its own may be responsible for noticing and language development (Williams, 2012). For this reason, research needs to examine students' individual reflection process on language when confronted with tasks.

Languaging using the writing modality was defined by Suzuki (2012) as written languaging as opposed to oral languaging. Both types of languaging differ not only in the way of verbalising reflections (written versus oral) but also in the demands of working memory capacities (Muñoz et al.,2006). Although there is scarce research examining the different effects of written versus oral reflection on language, some studies (Muñoz et al., 2006) comparing both types of reflection have acknowledged the cognitive superiority of the writing modality, due to its slower pace, which allows better engagement in cognitive processes for problem-solving, as well as more in-depth reflection in comparison to oral languaging (Williams, 2012).

Despite the potential relevance of written languaging to delve into students' noticing and understanding of errors, very few studies have explored the usefulness of languaging for feedback processing. A clear exception is the study conducted by Suzuki (2012), who asked 24 intermediate learners of English to language (i.e. write their own reflections) on the direct corrections that they received on a text they had previously written. The written reflection on errors was done distinguishing among grammar errors, lexical ones and errors that were not understood regardless of being grammatical or lexical. Suzuki's study (2012) showed that written languaging helped learners to successfully correct their grammatical and lexical errors when immediately revising their texts.

Although Suzuki's research offers evidence of the importance of intermediate L2 learners' engagement with direct feedback for L2 accuracy, it is still needed to investigate students' noticing of error types and feedback processing at low L2 proficiency levels using different feedback types so as to shed light on the potential effects of WCF types on L2 accuracy (grammar and non-grammar errors) and possible L2 acquisition (Sachs \& Polio, 2007) at low proficiency levels. The degree of noticing problems in output has been shown to differ according to students' L2 proficiency level (Qi \& Lapkin, 2001), which in turn also determines language development (Schmidt \& Frota, 1986). More specifically, more proficient students tend to notice more grammar mistakes than less proficient learners (Swain \& Lapkin, 1995). On the other hand, different feedback types promote distinct engagement in problem-solving activity that is needed for L2 accuracy and language learning.

The present study aims to contribute to Second Language Acquisition (SLA) research by shedding light on the LLP of writing through feedback processing in a written languaging session. We aimed at showing the possible relationship between learners' processing of two feedback types (direct and indirect) and the correction of errors (grammar and non-grammar) in rewritten texts. Our participants were secondary school students at a low L2 proficiency level, who were asked to reflect during a written languaging session on their errors corrected directly or indirectly so as to ensure the processing of feedback before rewriting their texts in a new writing session. 
The following research questions (RQs) were formulated following Suzuki (2012):

RQ1. Are there differences in participants' written languaging in response to direct and indirect feedback?

RQ2. Are there differences in the accuracy of immediately rewritten texts between feedback conditions (direct and indirect) following students' written languaging? RQ3. Does written languaging in response to direct and indirect feedback help to improve the accuracy of immediately rewritten texts?

\section{2. Мethod}

The participants were 30 English Foreign Language (EFL) students at a public secondary school whose English level corresponded to an elementary one (A2 level). The participants wrote an essay and then, they were divided into two groups so as to provide them with different feedback types: direct group (DG; $n=15)$ or indirect group (IG; $n=15)$. The groups were done after having confirmed the existence of similar number of words (DG: $\mathrm{M}=57.47, \mathrm{SD}=22.91$; IG: $\mathrm{M}=54.67 ; \mathrm{SD}=25.74$; Mann Whitney: $\mathrm{Z}=-.73, p=.49 ; \mathrm{r}=.13$ ) and percentages of errors (DG: $\mathrm{M}=17.60 ; \mathrm{SD}=10.06$; IG: $\mathrm{M}=13.59 ; \mathrm{SD}=6.25$; Mann Whitney: $\mathrm{Z}=-.98, p=.34, \mathrm{r}=.18$ ) in the first essay for the two groups.

\subsection{Instruments}

The instruments included two writing prompts and a languaging prompt. The written prompts were based on a personal experience so that the participants did not require specific knowledge which could prevent them from writing.

Prompt A: A foreign visitor has one day to spend in your country. Where should this visitor go on that day? Use specific reasons and details to support your idea.

Prompt B: People do many things to stay healthy. What do you do for good health?

Use specific reasons and details to support your answer.

The languaging prompts, which were provided in the students' L1 so as to make them feel confident when explaining the reasons for their mistakes, included the following questions following Suzuki's study (2012): “Why is this linguistic form incorrect/wrong?, why did the instructor give feedback on this form?

Although the participants were expected to provide reasons for the corrections when doing their written languaging, they were also allowed to write, as in Suzuki's research, "II do not know" if they did not find what was wrong and why. Participants were encouraged to think about their mistakes before using the "I do not know" answer. 
Florentina, Julio and María Ángeles The Language Learning Potential of Writing through EFL ...

\subsection{Data collection}

The first day, the participants wrote their essay in 50 minutes. Half of the students wrote their essays based on prompt A and the other half used prompt B. In this way, we counterbalanced the possible effects of the writing topic on linguistic accuracy. Three days later, the teacher gave feedback to all students making sure that half of the students who wrote their essays based on prompt A received direct feedback and the other half received indirect correction. The same process for the provision of feedback was followed with prompt B.

Participants were provided with unfocused corrective feedback in the same way as ordinary teachers usually give feedback on all types of errors rather than on a few selected ones, so as to ensure the ecological validity of the study. Participants who received direct feedback were provided with the correction of all linguistic errors that were noticed by the teacher. In the case of the indirect feedback group, the participants were provided with the correction of all the linguistic errors the participants made using metalinguistic corrections next to the errors such as verb form, word choice, preposition, or sentence structure.

On the same day that participants received feedback, they were asked to reflect on the provided corrections during 30 minutes in a languaging session since the essays were short (around 50 words). One week after the languaging session, the participants were given their original essays without corrections and were asked to rewrite them in 30 minutes. The rewriting session was carried out with their original essays but without corrections so that the changes made in the rewritten texts could be attributed to learners' feedback processing during the languaging session.

\subsection{Data coding}

The coding of the languaging and written texts was carried out by two experienced L2 teachers and researchers who coded together $100 \%$ of written language episodes (WLEs), errors in texts and incorporations of feedback into the rewritten texts.

The construct of WLE was based on the definition of language related episodes (LREs) or episodes of languaging understood as "any segment of the protocol in which a learner either spoke about a language problem s/he encountered while writing and solved it either correctly or incorrectly, or simply solved it (again either correctly or incorrectly) without having explicitly identified it as a problem" (Swain \& Lapkin, 1995: 378). We adapted this definition to the use of written languaging and the provision of feedback following Suzuki (2012). Therefore, WLEs were understood as learners' written explanation of the errors, either correctly or incorrectly, that had been previously corrected by the teacher using distinct feedback types (i.e. direct or indirect). Learners' languaging on errors was coded according to the type of metalinguistic explanations provided following Suzuki (2012). The coding resulted in the distinction of WLE in terms of grammar (i.e. verb form, verb tenses, articles, sentence structures, and prepositions), lexis (i.e. word choice, and spelling), or attempts of explaining the errors without really understanding the reason for the error (don't know WLE). This distinction of grammatical and lexical WLEs was important to investigate low L2 proficiency students' noticing and understanding of both grammar and non-grammar errors. 
As for the rewritten texts, we distinguished between those incorporations in the rewritten texts that had been successfully and unsuccessfully done (Suzuki, 2012). In addition, on some occasions learners carried out successful revisions of items that had not been previously languaged. These successful revisions were coded as "covert" (Hanaoka \& Izumi, 2012) since they were problems that were noticed by the learners, but they were not explicitly articulated in written languaging.

\subsection{Data analysis}

We computed the number and percentage of different types of WLEs in terms of lexis, grammar and 'don't know'. As for the accuracy of the original texts, we computed the number of words, and the percentage of errors. Regarding rewritten texts, we computed the percentage of incorporations that could be traced back to the participants' written language episodes, as in Suzuki's research (2012).With respect to the statistical analyses, we conducted Friedman tests, Wilcoxon signed rank tests and Mann Whitney U tests.

\section{RESUlts}

RQ1. Are there differences in participants' written languaging in response to direct and indirect feedback?

In order to examine learners' engagement with WLE, we first compared the percentage of WLEs $(\mathrm{DG}=51 \%$; $\mathrm{IG}=67 \%$ ). This percentage was computed taking into account the total number of WLEs $(\mathrm{DG}=70$; $I G=64)$ within each feedback condition in relation to the total number of errors (DG: 137; IG: 96). It should be noted that although the total number of errors in the DG seemed to be higher in the first essay than in the IG, the number of words in the first essay was also higher in the DG (Direct: $M=57.47, S D=22.91$; Indirect: $M=54.67$; $\mathrm{SD}=25.74)$. Therefore, the possibility of making errors also increased when the number of words rose ${ }^{1}$. As explained before, no significant differences between the two groups were found in the first essay regarding the number of words or the percentage of errors.

Although the participants in both feedback groups engaged in written languaging, they only reflected on half of the errors made and signaled with feedback. Participants in the IG tended to reflect on more errors in comparison with the DG (see \% of WLEs above). However, this tendency was not statistically significant $(U=84.50 ; Z=-1.17 ; p=.25 ; r=.21)$. As for the types of WLEs on which participants focused when analyzing their errors, a Friedman test indicated the existence of differences in the distribution of grammar, lexis and 'don't know' WLE within each feedback condition (table 1).

\footnotetext{
${ }^{1}$ For this reason, we compared both groups in terms of the percentage of errors and the percentage of WLEs
} 
Florentina, Julio and María Ángeles The Language Learning Potential of Writing through EFL ...

Table 1. Types of WLEs within each feedback condition

\begin{tabular}{|l|c|c|c|c|}
\hline \multirow{2}{*}{ WLEs } & \multicolumn{2}{|c|}{ DG } & \multicolumn{2}{c|}{ IG } \\
\cline { 2 - 5 } & $\mathrm{N}$ & $\%$ & $\mathrm{~N}$ & $\%$ \\
\hline Grammar & 39 & 56 & 27 & 42 \\
\hline Lexis & 12 & 17 & 6 & 9 \\
\hline Don't know & 19 & 27 & 31 & 49 \\
\hline Total & 70 & 100 & 64 & 100 \\
\hline Friedman test & \multicolumn{2}{|c|}{$\chi^{2}(2)=13.38, \mathrm{p}=.00$} & \multicolumn{2}{c|}{$\chi^{2}(2)=6.98, \mathrm{p}=.03$} \\
\hline
\end{tabular}

Wilcoxon signed rank tests were then conducted to find specific intra-group differences. Participants in both feedback groups reflected more on grammar errors than lexical ones (DG: $Z=-2.94, p=.00, r=.54 ;$ IG: $Z=2.50, p=.01, r=.46$ ). In addition, within the IG, participants tended to produce significantly more "don't know" WLEs than lexical ones (IG: $Z=-2.52$, $\mathrm{p}=.01, \mathrm{r}=.46$ )

Regarding the percentage of WLEs, there were no significant differences in the total percentage of WLEs or in the different types (i.e. grammar, lexis, don't know) of WLEs between feedback conditions. It is also important to notice that "don't know" WLEs appeared to predominate, at least from a descriptive point of view in the case of the IG in comparison with the DG. However, a Mann Whitney U test (see table 2) indicated that there were no significant differences between feedback groups in this type of WLEs (i.e., "don't know"), as a result of the existence of high individual variability within each group.

Table 2. Comparison of different types of WLEs between feedback conditions

\begin{tabular}{|l|c|c|c|c|c|}
\hline \multirow{2}{*}{ Percentage of WLEs } & DG & \multicolumn{3}{|c|}{ Mann Whitney U test } & IG \\
\cline { 2 - 6 } & $\mathrm{M}(\mathrm{SD})$ & $\mathrm{Z}$ & $p$ & $\begin{array}{c}\text { Effect size } \\
(\mathrm{r})\end{array}$ & M (SD) \\
\hline Grammar & $\begin{array}{c}53.43 \\
(32.59)\end{array}$ & -1.38 & .17 & .25 & $\begin{array}{c}37.41 \\
(32.83)\end{array}$ \\
\hline Lexis & $\begin{array}{c}15.09 \\
(15.46)\end{array}$ & -1.30 & .25 & .24 & $\begin{array}{c}8.92 \\
(14.89)\end{array}$ \\
\hline Don't know & $\begin{array}{c}24.82 \\
(33.23)\end{array}$ & -1.47 & .16 & .27 & $\begin{array}{c}47 \\
(37.99)\end{array}$ \\
\hline Total & $\begin{array}{c}57.27 \\
(28.59)\end{array}$ & -1.17 & .25 & .21 & $\begin{array}{c}68.61 \\
(31.30)\end{array}$ \\
\hline
\end{tabular}


As a whole, these findings indicate that (i) the type of WCF did not have any bearing in the overall production of written languaging between feedback groups; (ii) participants in both groups did not tend to engage in rich languaging since only around fifty percent of the errors made were reflected on; (iii) there were no significant differences in any types of WLEs between both groups; (iv) written reflection on grammar errors predominated over lexical ones in both feedback groups; (v) within the IG, there were significantly more unresolved interpretations of language problems or "don't know" WLEs than lexical reflection.

RQ2. Are there differences in the accuracy of immediately rewritten texts between feedback conditions (direct and indirect) following students' written languaging?

The participants in both feedback groups wrote a similar number of words (DG: Wilcoxon test: $Z=-.32, p=.75, r=.05$; IG Wilcoxon test: $Z=-.72, p=.47, r=.13$; IG) in both their initial (DG: $M=57.47, S D=22.91$; IG: $M=54.67 ; S D=25.74$ ) and rewritten texts (DG: $\mathrm{M}=57.27, \mathrm{SD}=23.29$; IG: $\mathrm{M}=54.20 ; \mathrm{SD}=25.39)$. The participants in both groups were more accurate in their rewritten texts (DG: \% of errors initial text: $M=17.60, S D=10.06 ; \%$ of errors rewritten text: $\mathrm{M}=4.96, \mathrm{SD}=6.76$; Wilcoxon: $\mathrm{Z}=-3.30, \mathrm{p}=.00, \mathrm{r}=.60$; IG: \% of errors initial text: $\mathrm{M}=13.59, \mathrm{SD}=6.25$; \% of errors rewritten text: $\mathrm{M}=10.08, \mathrm{SD}=8.01$; Wilcoxon: $\mathrm{Z}=-2.98, \mathrm{p}=.00, \mathrm{r}=.54)$. However, the $\mathrm{DG}$ was significantly more accurate in the rewritten texts compared to the IG (Mann Whitney: $\mathrm{Z}=-2.30, \mathrm{p}=.02, \mathrm{r}=.42$ )

RQ3. Does written languaging in response to direct and indirect feedback help to improve the accuracy of immediately rewritten texts?

Regarding the total number of incorporations, the DG significantly incorporated more number of changes $(n=71)$ in their rewritten texts $(\mathrm{U}: 52.50 ; \mathrm{Z}=-2.52 ; \mathrm{p}=.01 ; \mathrm{r}=.46)$ compared to the IG $(n=32)$. As for the frequency of successful incorporations, they tended to be higher than unsuccessful incorporations in both feedback conditions (DG; Wilcoxon: $Z=-2.71, p=.01$, $\mathrm{r}=.49$; IG; Wilcoxon: $\mathrm{Z}=-2.42, \mathrm{p}=.01, \mathrm{r}=.44$ ). Those successful incorporations were mostly related to grammar with few and anecdotal lexical exceptions given the predominance of grammatical WLEs.

Table 3. Types of incorporation in rewritten texts

\begin{tabular}{|l|c|c|c|c|}
\hline \multirow{2}{*}{ Types of Incorporations } & \multicolumn{2}{|c|}{ DG } & \multicolumn{2}{c|}{ IG } \\
\cline { 2 - 5 } & $N$ & $\%$ & $N$ & $\%$ \\
\hline Successful & 47 & 66.20 & 21 & 65.63 \\
\hline Unsuccessful & 7 & 9.86 & 6 & 18.75 \\
\hline
\end{tabular}


Florentina, Julio and María Ángeles The Language Learning Potential of Writing through EFL ...

\begin{tabular}{|l|c|c|c|c|}
\hline Covert & 17 & 23.94 & 5 & 15.63 \\
\hline Total & 71 & 100 & 32 & 100 \\
\hline Friedman test & \multicolumn{2}{|c|}{$\chi^{2}(2)=8.12 \mathrm{p}=.02$} & \multicolumn{2}{|c|}{$\chi^{2}(2)=7.26, \mathrm{p}=.03$} \\
\hline
\end{tabular}

Successful incorporations predominated over both unsuccessful and covert incorporations in both feedback groups (table 3). No differences in successful, unsuccessful or covert incorporations were found between both feedback conditions (see table 4), although the DG tended to have more covert incorporations than the IG (table 3).

Table 4. Comparison of incorporations between feedback conditions

\begin{tabular}{|l|c|c|c|c|c|}
\hline \multirow{2}{*}{$\begin{array}{l}\text { Percentage of } \\
\text { Incorporations }\end{array}$} & DG & \multicolumn{3}{|c|}{ Mann Whitney U test } & IG \\
\cline { 2 - 6 } & $\mathrm{M}(\mathrm{SD})$ & $\mathrm{Z}$ & $p$ & $\begin{array}{c}\text { Effect size } \\
(\mathrm{r})\end{array}$ & $\mathrm{M}$ (SD) \\
\hline Successful & $\begin{array}{c}60.98 \\
(41.87)\end{array}$ & -.02 & 1 & .00 & $\begin{array}{c}56.67 \\
(46.20)\end{array}$ \\
\hline Unsuccessful & $\begin{array}{c}9.78 \\
(19.13)\end{array}$ & -.15 & .90 & .03 & $\begin{array}{c}12.78 \\
(23.75)\end{array}$ \\
\hline Covert & $\begin{array}{c}22.57 \\
(28.74)\end{array}$ & -1.34 & .25 & .24 & $\begin{array}{c}10.55 \\
(19.02)\end{array}$ \\
\hline
\end{tabular}

The main findings show that: (i) the DG incorporated significantly more changes in the rewritten texts than the IG; (ii) both feedback groups tended to successfully incorporate rather than unsuccessfully integrate in their rewritten essays the feedback on which they had previously reflected (iii) there were covert incorporations in both feedback conditions, but particularly in the DG.

\section{Discussion}

The present study aimed to investigate the LLP of writing through feedback processing in a languaging session. Our findings will be discussed in relation to learners' feedback processing and the accuracy of the rewritten texts.

\subsection{Participants' feedback processing}

Learners' feedback processing was explored in terms of the total amount of WLEs and the types of WLEs. As for the amount of WLEs, both feedback groups reflected on half (DG: 
$51 \%$ ) or slightly more than half (IG: $67 \%$ ) of the errors that were made and signaled with feedback, probably due to their low L2 proficiency level. Along these lines, previous studies have found that L2 proficiency is a major determinant of the degree of meta-linguistic reflection engaged in by learners (Sheen, 2007). More proficient learners have been reported to reflect more on their language problems through the generation of LREs when writing in collaboration (Leeser, 2004); when composing on an individual basis (Qi \& Lapkin, 2001); or when involved in the writing of multi-stage composition tasks intended to provide them with written feedback (Hanaoka, 2007). Our findings are in clear contrast to the results reported by Suzuki (2012) whose participants, Japanese university students at an intermediate level of L2 proficiency taking an English writing course at university, produced a similar number of WLEs to the direct corrections provided to them by the teacher. We could therefore suggest that L2 proficiency level could determine the extent to which learners process all or just part of the feedback with which they have been provided.

The IG tended to reflect on more errors than the DG. However, a detailed analysis of the data showed that the IG reported "don't know" WLEs in almost half of the episodes $(49 \%)$ in which they engaged. Accordingly, the IG engaged in simple noticing processes (Kuiken \& Vedder, 2002; Leow, 1997), which did not result in problem-solving and in high retention of errors when rewriting their texts. The purported superiority of indirect feedback in prompting problem-solving was not shown with our EFL students since they could not engage in elaborate noticing that could result in metalinguistic awareness for language learning (Leow, 1997). Our findings are consistent with previous studies that indicate that (i) low L2 proficiency students find it difficult to engage in reflection on form (Leeser, 2004); (ii) learners at low L2 proficiency levels struggle to understand their problems in writing when provided with implicit feedback since they have limited L2 knowledge that influences the capacity to assess the source and reasons of linguistic problems (Qi \& Lapkin, 2001).

Regarding the types of languaging that were produced in both feedback conditions, grammar episodes clearly predominated over lexical episodes, as it was also the case of Suzuki's research (2012). This finding is explained by the fact that our participants tended to make more grammatical errors. Therefore, they also had more opportunities to reflect on grammar rather than on lexis due to the tailored feedback they received either directly or indirectly. The composition of personal narratives resulted in more grammatical errors because the participants only used a limited range of words that they knew to describe their personal experiences. They were not forced to express complex ideas or use words that they did not know since they did not have to narrate the events that appeared in pictures as it was the case of other studies (e.g. Hanaoka \& Izumi, 2012; Martínez Esteban \& Roca de Larios, 2010). As for feedback processing, the tailored feedback (direct or indirect) on their errors did not push our participants to notice lexical holes in their intended production as it could have happened with other feedback types such as reformulations or models for which learners may notice linguistic gaps and holes (Swain, 1998) and/or lexical problems in their written production that can stand out comparing their written texts to those reformulations and models (e.g., Hanaoka, 2007; Hanaoka \& Izumi, 2012; Martínez Esteban \& Roca de Larios, 2010;).These findings are consistent with previous research that has reported that tasks corrected by direct feedback lead to more grammar reflection (e.g. Suzuki, 2012). Furthermore, our results 
Florentina, Julio and María Ángeles The Language Learning Potential of Writing through EFL ...

indicate that this grammatical reflection based on distinct feedback types can lead to grammatical improvement at low L2 proficiency levels, especially if the feedback is direct.

\subsection{Accuracy of rewritten texts}

The participants in both groups improved the accuracy of their rewritten texts. There was no avoidance of errors since the number of words was similar in the initial and rewritten texts. In addition, the errors that were reflected on (basically grammatical) and understood tended to be also successfully incorporated in the rewritten texts. We can deduce that the improvement of L2 acccuracy for both feedback groups was the outcome of the conjoined effects of feedback and feedback processing through written languaging. In both feedback groups, the percentage of successful incorporations was significantly higher than unsuccessful or covert incorporations. These findings are in line with previous studies that indicate that oral and written languaging can mediate L2 acccuracy (Hanaoka, 2007; Suzuki, 2012). Our results also expand previous research findings about WCF by showing the beneficial effects of distinct feedback types in accuracy improvement and, more specifically grammatical improvement, at low L2 levels, which could ultimately lead to L2 development. Furthermore, our findings show the effectiveness of learners' retention of feedback one week after a languaging session in contrast to Suzuki's research (2012) in which the participants rewrote their essays immediately after the languaging session. We could suggest that in the case of Suzuki's study (2012), the participants could remember the corrections because they had just received them and reflected on them, but those findings do not show retention of feedback across time that could lead to language learning. Nevertheless, our results cannot be considered illustrative of language learning for which the production of new written texts would have been needed to show the long-term effects of WCF.

As pointed out before, the participants in both feedback groups only engaged in written languaging in half of the highlighted errors, which in turn resulted in a similar number of incorporations of changes in the rewritten texts. Therefore, only half of the targeted errors with different feedback types was understood and successfully corrected, similarly to what has been found in EFL university students (Kim, 2013). Taking into account a language learning perspective, these results empirically show that the effectiveness of different types of corrective feedback depends on the extent to which learners previously process and understand the feedback provided (Bitchener \& Storch, 2016). In other words, WCF may be not fully effective due to the complexity of the correction process (Truscott, 1996) in which it is needed not only to provide appropriate feedback but also that students process the feedback and understand the error and the correction. If learners do not reflect on the errors on which they receive feedback, they cannot understand the correction, which in turn could lead to learning (Schmidt, 1990). Furthermore, the mere provision of feedback at low L2 proficiency levels does not guarantee the processing and understanding of all errors. This lack of feedback processing and/or understanding of feedback and errors together with other well-documented research design flaws (see Guénette, 2007 for a discussion) could explain the ineffectiveness of WCF reported in some studies that had exclusively focused on the analysis of written products.

In our study, the accuracy of the rewritten texts was significantly higher in the DG given that (i) the IG tended to understand the error and the feedback to a lesser extent 
compared to the DG as shown by the high percentage of don't know WLEs; (ii) the DG tended to incorporate more covert changes in their rewritten texts than the IG. The presence of covert incorporations is consistent with those of previous studies that indicate the existence of changes in their rewritten texts, which have been highlighted through different types of feedback (reformulations or models), but on which participants have not explicitly reflected (Hanaola, 2006; Hanaoka \& Izumi, 2012). In the case of the DG, the correction of some errors was so evident (e.g. everyworld instead of everybody) that the participants may have noticed and understood their errors and the corrections without commenting on them. We suggest that the provision of direct feedback in a written way ensured learners' noticing and understanding of some obvious errors without necessarily making students write down the reason for them. It is possible that oral languaging could have uncovered reflection processes on some errors that our written languaging could not detect since our participants could have noticed and understood some errors, but they may not have verbalised them in their written languaging session.

Taking into account that the DG produced rewritten texts that were significantly more accurate than those of the IG, we conclude that direct feedback could be more effective for improving the accuracy of low L2 proficiency learners provided that learners had previously processed and understood the feedback. The IG seemed to find more problems to retain the corrections because they also found more challenging to understand the corrections provided, which resulted in significantly worse L2 accuracy in their rewritten texts.

In light of these results, teachers should encourage students to reflect on their received feedback using journals or portfolios so as to make sure learners not only notice errors through feedback types, but they also understand feedback and learn from it. This reflection on errors after receiving feedback could be more effective to promote L2 accuracy and learning rather than the mere provision of abundant feedback using distinct feedback types. Furthermore, teachers should be trained in techniques like the ones tested in this study so as to help students to process feedback and notice gaps between their interlanguage and the target language using the feedback provided.

\section{Conclusion}

This study helps to advance SLA research by showing the positive effects of learners' processing of two different feedback types on the improvement of linguistic accuracy (Swain, 2006) at low L2 proficiency levels. Most importantly, the study shows that regardless of the feedback type, half of the feedback provided can be rendered ineffective if students do not notice and/or do not understand the targeted errors or feedback. In this respect, this study opens a new window into the LLP of writing by showing that the effectiveness of feedback on L2 accuracy and possible L2 development is related to feedback processing. Several studies (see Manchón, 2011, for a review) have shown that the production of output when writing and the provision of feedback can result in language development. Our study shows that this LLP derives from the accurate processing of corrective feedback for which it is needed to delve into the noticing and understanding of errors rather than inferring students' processing of errors from performance. Future studies should investigate individual differences 
Florentina, Julio and María Ángeles The Language Learning Potential of Writing through EFL ...

in feedback processing and the possible quantitative and qualitative differences in the depth of processing, which may determine the effectiveness of feedback for L2 development across time.

\section{ACKNowledgements}

The research reported in this paper is part of the work conducted within two research projects financed by the Spanish Ministerio de Economía y Competitividad (research grant FFI 2016-79763-P) and by Fundación Séneca (19463/PI/14).

\section{REFERENCES}

Bitchener, J. (2012). "A reflection 'on the language learning potential' of written CF", in Journal of Second Language Writing, 21, 4: 348-363.

Bitchener, J., \& Knoch, U. (2008). "The value of written corrective feedback for migrant and international students", in Language Teaching Research, 12, 3: 409-431.

Bitchener, J., \& Storch, N. (2016). Written corrective feedback for L2 development. Bristol, UK: Multilingual Matters.

Chandler, J. (2003). "The efficacy of various kinds of error feedback for improvement in the accuracy and fluency of L2 student writing”, in Journal of Second Language Writing, 12: 267-296.

Ellis, R., \& Shintani, N. (2013). Exploring Language Pedagogy through Second Language Acquisition Research. London: Routledge.

Fortune, A., \& Thorp, D. (2001). "Knotted and entangled: New light on the identification, classification and value of language related episodes in collaborative output tasks", in Language Awareness, 10, 2:143-160.

Guénette, D. (2007). "Is feedback pedagogically correct? Research design issues in studies of feedback on writing", in Journal of Second Language Writing, 16, 1:40-53.

Hanaoka, O. (2006). "Noticing from models and reformulations: A case study of two Japanese EFL Learners", in Sophia Linguistics, 54: 167-192.

Hanaoka, O. (2007). "Output, noticing, and learning: An investigation into the role of spontaneous attention to form in a four-stage writing task", in Language Teaching Research, 11, 4: 459-479.

Hanaoka, O., \& Izumi, S. (2012). "Noticing and uptake: Addressing pre-articulated covert problems in L2 writing", in Journal of Second Language Writing, 21, 4: 332-347.

Kim, J.H. (2013). "Learner understanding of written corrective feedback and its relationship with immediate uptake and retention in EFL classrooms", in English Teaching, 68, 3: 109-130.

Kuiken, F., \& Vedder, I. (2002). "Collaborative writing in L2: The effect of group interaction on text quality", in S. Ransdell and M. Barbier (eds.), New Directions for Research in L2 Writing. Dordrecht: Kluwer, 168-188.

Kuiken, F., \& Vedder, I. (2008). "Cognitive task complexity and written output in Italian and French as a foreign language", in Journal of Second Language Writing, 17,1:48-60.

Leow, R. (1997). "Attention, awareness, and foreign language behavior", in Language Learning, 47, 3: 467-505.

Leeser, M.J. (2004). "Learner proficiency and focus on form during collaborative dialogue", in Language Teaching Research, 8, 1: 55-81.

Mackey, A., Gass, S., \& McDonough, K. (2000). "How do learners perceive interactional feed- 
back?", in Studies in Second Language Acquisition, 22, 4: 471-497.

Manchón, R.M. (2011). "Writing to learn the language. Issues in theory and research", in R.M. Manchón (ed.), Learning-to-write and writing-to-learn in an additional language. Amsterdam: John Benjamins, 61-82.

Martínez Esteban, N., \& Roca de Larios, J. (2010). "The Use of Models as a Form of Written Feedback to Secondary School Pupils of English", in International Journal of English Studies, 10, 2: 143-170.

Muñoz, B., Magliano, J. P., Sheridan, R., \& McNamara, D. S. (2006). "Typing versus thinking aloud when reading: Implications for computer-based assessment and training tools", in Behavior Research Methods, 38, 2: 211-217.

Qi, D. S., \& Lapkin, S. (2001). "Exploring the role of noticing in a three-stage second language writing task", in Journal of Second Language Writing, 10, 4:277-303.

Sachs, R., \& Polio, C. (2007). "Learners' uses of two types of written feedback on a L2 writing revision task", in Studies in Second Language Acquisition, 29, 1:67-100.

Schmidt, R. (1990). "The Role of Consciousness in Second Language Learning", in Applied Linguistics, 11, 2: 129-158

Schmidt, R., \& Frota, S. (1986). "Developing basic conversational ability in a second language: A case study of an adult learner of Portuguese", in R.R. Day (ed.), Talking to learn: Conversation in second language acquisition. Rowley, MA: Newbury House, 237-326.

Sheen, Y. (2007). "The effects of focused written corrective feedback and language aptitude on ESL learners' acquisition of articles", in TESOL Quarterly, 41, 2: 255-283.

Shintani, N., \& Ellis, R. (2013). "The comparative effect of direct written corrective feedback and metalinguistic explanation on learners' explicit and implicit knowledge of the English indefinite article", in Journal of Second Language Writing, 22, 3: 286-306.

Suzuki, W. (2012). "Written Languaging, Direct Correction, and Second Language Writing Revision", in Language Learning, 62, 4: 1110-1133.

Swain, M. (1995) "Three functions of output in second language learning", in G. Cook, and B. Seidelhofer(eds.), Principle and Practice in Applied Linguistics: Studies in Honor of H.G. Widdowson. Oxford: Oxford University Press, 125-144.

Swain, M. (1998). "Focus on form through conscious reflection", in C. Doughty \& J. Williams (eds.), Focus on form in classroom second language acquisition. Cambridge: Cambridge Universty Presss, 64-81.

Swain, M. (2006). "Languaging agency and collaboration in advanced language proficiency", in H. Byrnes (ed.), Advanced language learning: The contribution of Halliday and Vygotsky. London: Continuum, 95-108

Swain, M., \& Lapkin, S. (1995). "Problems in output and the cognitive processes they generate: A step towards second language learning", in Applied Linguistics, 16: 371-391

Truscott, J. (1996). "The Case Against Grammar Correction in L2 Writing Classes", in Language Learning, 46, 1: 327-369

Truscott, J. (2007). "The effect of error correction on learners' ability to write accurately", in Journal of Second Language Writing 16: 255-272.

Williams, J. (2012). "The potential role(s) of writing in second language development", in Journal of Second Language Writing, 21 , 4: 321-331. 